UDC 930.85/73.05

Submitted: 25.11 .2018

LBC 63.3(2)44

Accepted: 14.03.2019

\title{
THE EVENTS AND PARTICIPANTS OF THE TIME OF TROUBLES IN THE RUSSIAN MEMORIAL CULTURE ${ }^{1}$
}

\author{
Evgeny F. Krinko \\ Southern Scientific Center, RAS, Rostov-on-Don, Russian Federation \\ Evgeniya M. Goryushina \\ Southern Scientific Center, RAS, Rostov-on-Don, Russian Federation
}

\begin{abstract}
Introduction. The study of historical memory has recently become one of the most relevant research areas. The Time of Troubles of the early $17^{\text {th }}$ century is one of the most acute socio-political crises in the history of the country which has been arousing the interest of many historians. At the same time, the features of reflecting events and participants of the Time of Troubles in various forms of historical memory are becoming the subject of special studies. Methods and materials. The authors used the institutional approach, general scientific methods of logical analysis, the comparative historical and problem chronological methods, the situational analysis. The article is based on the authors' field observations, historiographic sources and mass media publications. Analysis. Three periods can be distinguished in the memorialization of events and participants of the Time of Troubles: pre-revolutionary, Soviet, and post-Soviet. They are closely related to the periods in the history of the Russian and Soviet states and the policy of memory. In addition, each of them is divided into two stages. Results. In the $17^{\text {th }}-18^{\text {th }}$ centuries, honoring events, heroes and martyrs of the Time of Troubles took religious forms. In the $19^{\text {th }}$ century, the policy of memory was separated from the church and became an independent area of activity. But its dependence on the state was increasing, especially in the era of Nicholas I's reign. This was evidenced by forming the cult of Susanin. The largest ideological campaign of imperial Russia which caused a significant increase in the number of memorial events and objects dedicated to the Time of Troubles was the celebration of the $300^{\text {th }}$ anniversary of the House of Romanov. After the revolution of 1917, a program of monumental propaganda was implemented. It included overthrowing old monuments of the monarchy and establishing new ones, including ones dedicated to popular movements and their leaders, and Bolotnikov was one of them. Closing and destructing temples acquired a massive character. It involved temples dedicated to the Time of Troubles as well. But since the late 1930s, Soviet policy of memory returned to patriotic principles, which led to creating new monuments to Susanin, Minin and Pozharsky. The modern period in the Soviet policy of memory development is characterized by restoring destroyed temples and erecting new monuments to participants of the Time of Troubles, including those who were "omitted figures". National Unity Day gave a significant impetus to creating memorial objects in honor of the events and heroes of the Time of Troubles. Monuments of regional and local significance appeared in many places. They were designed not only to "fit" the fate of a particular locality into the general history of the a country, but also to make it more attractive for tourists.

¿ Key words: the Time of Troubles, memorial culture, policy of memory, Kuzma Minin, Dmitry Pozharsky,

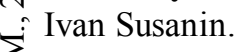

Citation. Krinko E.F., Goryushina E.M. The Events and Participants of the Time of Troubles in the Russian Memorial Culture. Vestnik Volgogradskogo gosudarstvennogo universiteta. Seriya 4, Istoriya. Regionovedenie. Mezhdunarodnye otnosheniya [Science Journal of Volgograd State University. History. Area Studies. International Relations], 2019, vol. 24, no. 2, pp. 203-214. (in Russian). DOI: https://doi.org/10.15688/jvolsu4.2019.2.17
\end{abstract}




\title{
СОБЫТИЯ И УЧАСТНИКИ СМУТНОГО ВРЕМЕНИ В МЕМОРИАЛЬНОЙ КУЛЬТУРЕ РОССИИ ${ }^{1}$
}

\author{
Евгений Федорович Кринко \\ Южный научный центр РАН, г. Ростов-на-Дону, Российская Федерация \\ Евгения Михайловна Горюшина \\ Южный научный центр РАН, г. Ростов-на-Дону, Российская Федерация
}

\begin{abstract}
Аннотация. Изучение исторической памяти сравнительно недавно превратилось в одно из наиболее актуальных исследовательских направлений. Смута начала XVII в. стала одним из самых острых социальнополитических кризисов в истории страны, который вызывал и продолжает вызывать интерес многих историков. В то же время особенности отражения событий и участников Смутного времени в различных формах исторической памяти только становятся предметом специальных исследований. Авторы использовали институциональный подход, общенаучные методы логического анализа, сравнительно-исторический и проблемно-хронологический методы, ситуационный анализ. Статья основана на полевых наблюдениях, историографических источниках и публикациях в СМИ. В мемориализации событий и участников Смутного времени можно выделить три периода: дореволюционный, советский и постсоветский. Они тесно связаны с периодами в истории Российского и Советского государства и политикой памяти. При этом каждый из них, в свою очередь, делится на два этапа. B XVII-XVIII вв. почитание событий, героев и мучеников Смугы принимало религиозные формы. В XIX в. мемориальная политика отделяется от церкви и становится самостоятельной сферой деятельности. При этом усиливается ее зависимость от государства, особенно в эпоху царствования Николая І. Об этом свидетельствует формирование культа Сусанина. Наиболее крупной идеологической кампанией императорской России, вызвавшей значительный рост числа мемориальных мероприятий и объектов, посвященных Смутному времени, стало празднование 300-летия Дома Романовых. После революции 1917 г. реализовалась программа монументальной пропаганды. Она предусматривала свержение прежних памятников монархам и установление новых, в том числе посвященных народным движениям и их лидерам, одним из которых считался Болотников. Массовый характер носило закрытие и разрушение храмов, в том числе и посвященных Смутному времени. При этом с конца 1930-х гг. советская мемориальная политика вернулась к патриотическим принципам, что привело к созданию новых памятников Сусанину, Минину и Пожарскому. Современный период в развитии советской мемориальной политики характеризуется восстановлением разрушенных храмов и установлением новых памятников участникам Смутного времени, в том числе тем, которые являлись «фигурами умолчания». Значительный импульс созданию мемориальных объектов в честь событий и героев Смутного времени придал День народного единства. Во многих местах появились памятники регионального и локального значения, призванные не только «вписать» судьбу отдельной местности в общую историю страны, но и придать ей дополнительную привлекательность в туристическом отношении.

Вклад авторов. В процессе подготовки исследования Е.Ф. Кринко осуществлял общее руководство, изучал особенности отражения событий и участников Смутного времени в мемориальной культуре, формулировал выводы, Е.М. Горюшина выявляла роль политических факторов в мемориальных процессах, корректировала результаты исследования.

Ключевые слова: Смутное время, мемориальная культура, политика памяти, Кузьма Минин, Дмитрий Пожарский, Иван Сусанин.

Цитирование. Кринко Е. Ф., Горюшина Е. М. События и участники Смугного времени в мемориальной культуре России // Вестник Волгоградского государственного университета. Серия 4, История. Регионоведение. Международные отношения. -2019. - Т. 24, № 2. - C. 203-214. -DOI: https://doi.org/10.15688/jvolsu4.2019.2.17
\end{abstract}

Введение. Изучение исторической памяти сравнительно недавно превратилось в одно из наиболее актуальных исследовательских направлений $[1 ; 2 ; 3 ; 6 ; 16 ; 19 ; 20 ; 26$; и др.]. Это свидетельствует о значительных изменениях в самом предмете исторических исследований, прежде посвященных непосредственно прошлому, а в последние годы все 
чаще обращающихся к механизмам и практикам его репрезентации. Особое внимание вызывает мемориальная культура как одна из важнейших форм исторической памяти [23; и др.]. Именно памятники, монументы, бюсты, барельефы и другие мемориальные объекты служат осязаемым воплощением исторических образов и представлений о реальных и легендарных личностях и событиях прошлого, придавая через материализацию легитимность их существованию. Апеллируя к прошлому, они на самом деле адресованы потомкам и выстраивают исторические события и их участников в определенной последовательности, выступают необходимым средством реализации политики памяти.

В этом отношении показательны практики увековечивания событий и участников Смутного времени начала XVII в. в мемориальной культуре России. Сопровождавшаяся крупными территориальными и людскими потерями, ослаблением власти и хозяйственным разорением Смута стала одним из самых острых социально-политических кризисов в истории страны, который вызывал и продолжает вызывать интерес многих историков [18; $21 ; 22 ; 24 ; 25$; и др.]. В то же время особенности отражения событий и участников Смутного времени в различных формах исторической памяти только становятся предметом специальных исследований [9; 27; и др.].

Методы и материалы. Статья опирается на институциональный подход, позволяющий рассматривать мемориальные объекты и соответствующие коммеморативные практики как системообразующие факторы в организации пространства исторической памяти, призванные закрепить в массовом сознании ту или иную версию прошлого, конструирующие определенную идентичность. Специфика предмета и содержания исследования предопределили выбор соответствующих источников. Помимо собственных полевых наблюдений авторов, основу работы составили историографические источники - исследования, посвященные событиям и героям Смутного времени, их отражению в исторической памяти, общим тенденциям в развитии мемориальной культуры, а также публикации в СМИ. При обращении к ним использовались общенаучные методы логического анализа, традиционный для историков сравнительноисторический метод, позволивший сопоставить мемориальные практики в различные периоды развития Российского государства, проблемно-хронологический метод изложения, наконец, ситуационный анализ, выражающийся в стремлении определить основные факторы, влияющие на динамику мемориальной ситуации. В настоящее время именно ситуационный подход, отталкивающийся от попытки «реконструировать весь ландшафт, набор акторов», которые участвуют в формировании политики памяти, утверждается в качестве одного из ведущих методов ее изучения именно в исторических исследованиях [19, с. 168].

Анализ. Доминирование религии и церкви в духовной жизни русского общества XVII в. порождало соответствующие формы увековечивания памяти о событиях Смутного времени в первые десятилетия по его завершении. На средства князя Д.М. Пожарского в Москве в память о победе был построен деревянный Казанский собор, освященный в 1625 году. В нем находилась главная войсковая святыня Второго ополчения - Казанская икона Божьей Матери. До 1765 г. к собору устраивались крестные ходы: 8 июля - в день обретения иконы в Казани, 22 октября - в день взятия Китай-города [5].

Главными героями Смутного времени считались личности, способствовавшие освобождению страны от захватчиков и выходу из кризиса, как достойные подражанию примеры служения государству, исполнения гражданского долга, в первую очередь руководители Второго ополчения Кузьма Минин и Дмитрий Пожарский. Прах Минина был погребен на погосте приходской Похвалинской церкви, а в 1672 г. - перенесен в Спасо-Преображенский собор Нижегородского кремля. Пожарский был похоронен в родовой усыпальнице в суздальском Спасо-Евфимиевом монастыре. После пресечения рода Пожарских усыпальница была заброшена. Но раскопки А.С. Уварова в середине XIX в. обнаружили сохранившиеся склепы и гробницы, над которыми в 1885 г. по проекту А.М. Горностаева был сооружен мраморный мавзолей.

В 1803 г. Вольное общество любителей словесности, наук и художеств Санкт-Петербурга предложило собрать средства на созда- 
ние в Нижнем Новгороде памятника в честь героев Второго ополчения. Однако Александр I не поддержал идею по финансовым соображениям $[10$, с. 86$]$. Тем не менее на следующий год скульптор И.П. Мартос подготовил проект памятника. В 1808 г. по инициативе жителей Нижнего Новгорода состоялся конкурс, победу в котором одержал доработанный проект Мартоса. Со следующего года началась всероссийская подписка на строительство памятника. При этом только в 1818 г. в Москве на Красной площади перед Верхними торговыми рядами (сейчас ГУМ) был открыт монумент высотой более 8 м. Выполненные в классическом стиле бронзовые скульптуры Минина и Пожарского возвышались на гранитном пьедестале с бронзовыми барельефами. Над передним была надпись: «Гражданину Минину и князю Пожарскому благодарная Россия лета 1818 г.». В Нижнем Новгороде на собранные средства был установлен гранитный обелиск по проекту архитектора А.И. Мельникова с барельефами по эскизам И.П. Мартоса.

Фигуры Минина и Пожарского вместе с царем Михаилом Федоровичем составили одну из шести главных скульптурных групп среднего яруса памятника «Тысячелетие России», воздвигнутого в Великом Новгороде в 1862 г. по проекту скульпторов М.О. Микешина, И.Н. Шредера и архитектора В.А. Гартмана. Сами скульптуры были выполнены Р.К. Залеманом и символизировали избрание новой династии как одно из важнейших событий истории России [12, с. 61]. Среди горельефов фриза нижнего яруса памятника также были представлены участники событий Смутного времени: патриархи Гермоген и Филарет, Михаил Романов, Минин и Пожарский, Авраамий Палицын и Иван Сусанин.

Объектами почитания стали и судьбы двух московских патриархов, проявивших стойкость духа в условиях тяжелых испытаний Смутного времени, - свергнутого Лжедмитрием I Иова и особенно Гермогена, призывавшего к освобождению Москвы от поляков и умершего в заточении от голода. В 1652 г. их останки были перенесены из гробниц в Старицком Успенском и Чудовом монастырях в Успенский собор. Мученичеству Гермогена впоследствии было посвящено немало картин.
Приезд Екатерины II в Кострому в 1767 г. положил начало официальному признанию Ивана Сусанина спасителем будущего царя Михаила Романова. В честь него был создан целый ряд музыкальных и художественных произведений [17]. Хотя многие исследователи указывали на отсутствие достоверных сведений о подвиге героя, при Николае I прославление Сусанина как отдавшего жизнь за царя крестьянина стало одним из направлений мемориальной политики, хорошо вписывавшимся в официальную идеологию того времени. В 1851 г. по императорскому указу на центральной площади Костромы, получившей к этому времени название Сусанинской, был возведен памятник Михаилу Федоровичу и Ивану Сусанину скульптора В.И. Демут-Малиновского. Он представлял собой колонну из красного гранита, увенчанную бюстом Михаила Романова в шапке Мономаха. В верхней части колонны был изображен государственный герб - двуглавый орел, в средней части - герб Костромской губернии. У основания находилась коленопреклоненная фигура молившегося Сусанина, слева лежали две жалованные грамоты его потомству. Барельеф на передней стороне постамента изображал сцену убийства Сусанина поляками. На задней стороне золотыми буквами было написано: «Ивану Сусанину, за Царя, спасителя веры и царства, живот свой положившему. Благодарное потомство». В 1900 г. вокруг памятника был разбит сквер, также получивший название Сусанинского.

Особое место в мемориальной истории Смуты занимала память о царевиче Дмитрии Ивановиче. Комиссия, расследовавшая «угличское дело», отказалась признать причиной его смерти убийство, и первоначально Дмитрий был погребен в Угличе, в дворцовом храме в честь Преображения Господня. В память о нем стали служить заупокойные службы с появлением Лжедмитрия I, выдававшего себя за чудесно спасшегося царевича. После прихода к власти Василия Шуйского утвердилась новая официальная версия об убийстве Дмитрия агентами Годунова, чтобы развеять все слухи о его спасении. В июне 1606 г. могила царевича была вскрыта, останки канонизированы и перенесены в Архангельский собор Московского Кремля - место захоронения 
большинства русских великих и удельных князей, царей и их ближайших родственников. В том же году царевич был причислен к лику святых. Во время правления первых Романовых, пострадавших в свое время от Годуновых, версия об убийстве царевича оставалась общепризнанной, найдя соответствующее отражение во многих последующих художественных произведениях. В 1630 г. на месте его гибели была построена деревянная, а в 1692 г. - каменная церковь Димитрия на крови. C XVIII в. образ царевича Дмитрия был помещен на гербе, а с 1999 г. - и на флаге города Углича.

Тела Федора и Марии Годуновых вместе с телом Бориса Годунова, извлеченным из гробницы в Архангельском соборе, захоронили в 1605 г. по приказу Лжедмитрия I без всяких почестей в женском Варсонофьевском монастыре в Москве. В 1606 г. по распоряжению Василия Шуйского останки Годуновых торжественно перенесли в Троице-Сергиев монастырь. Позже к ним присоединили тело умершей в 1622 г. Ксении Годуновой, в иночестве Ольги. В 1783 г. над гробницами Годуновых была возведена усыпальница, где они и покоятся до сих пор. Останки умершего в польском плену Василия Шуйского были возвращены в Россию в 1635 г. и перезахоронены в Архангельском соборе.

В течение двух столетий фактически не вспоминали о роли талантливого полководца М.В. Скопина-Шуйского, поскольку его прославление было невыгодно первым Романовым и их окружению, в котором находилось немало бывших «тушинцев» [11]. Только в середине XIX в. его образ стал приобретать популярность, но специальных памятников в его честь так и не появилось. О судьбах других персонажей Смутного времени в мемориальной культуре Российской империи фактически умалчивалось, хотя многие из них нашли свое отражение в художественных и музыкальных произведениях. Особенно часто привлекал внимание не только российских, но и иностранных писателей, композиторов и художников образ самозванца Лжедмитрия I.

Значительный подъем общественного интереса к событиям Смутного времени вызвала крупномасштабная мемориальная кампания в честь 300-летия Дома Романовых в
1913 году [8]. По всем городам России служили благодарственные молебны, проходили парады, давались торжественные балы, обеды и приемы губернаторами и градоначальниками, устраивались выставки и народные гуляния. В Москве в 1914 г. у входа в Верхний (сейчас Александровский) сад был возведен гранитный обелиск архитектора С.А. Власьева, увенчанный двуглавым орлом. На основании обелиска были изображены Георгий Победоносец, гербы Великих княжеств, губерний и областей России. Вверху располагался герб бояр Романовых - грифон с мечом и щитом, ниже были написаны имена царей и императоров из династии Романовых. В Костроме заложили фундамент памятника по проекту скульптора А.И. Адамсона, который должен был стать главным мемориалом в честь правящей династии. Он представлял собой часовню - ступенчатую башню высотой в 36 м с многоярусным шатровым завершением, увенчанным двуглавым орлом. На уступах располагались фигуры Романовых и связанных с их правлением выдающихся людей, включая Михаила Федоровича, его отца - патриарха Филарета, мать - инокиню Марфу, умирающего Сусанина, Минина и Пожарского. К 1917 г. был сооружен постамент и установлена часть бронзовых фигур. В Нижнем Новгороде на Благовещенской площади был заложен памятник Минину и Пожарскому по проекту скульптора В.Л. Симонова. В СанктПетербурге - храм в честь Феодоровской иконы, главный придел которого освятили в 1914 году. В дачном селении Тярлево (сейчас поселок Пушкинского района города СанктПетербурга) в том же 1914 г. освятили церковь Спаса Преображения. В Твери в 1916 г. был освящен Воскресенский собор. Храмы и часовни в честь 300-летия Дома Романовых были сооружены в Вильно (сейчас Вильнюс), Севастополе, Ново-Николаевске (сейчас Новосибирск) и других местах. Патриарх Гермоген в 1913 г. был прославлен в лике святых как священномученик, став Ермогеном.

Революция 1917 г. привела к кардинальным переменам в мемориальной политике. Пришедшие к власти большевики провозгласили программу монументальной пропаганды, считая ее важнейшим средством мобилизации масс на решение задач коммунистичес- 
кого строительства. Ее основы были закреплены декретом СНК РСФСР «О снятии памятников, воздвигнутых в честь царей и их слуг, и выработке проектов памятников Российской Социалистической Революции» от 14 апреля 1918 года. Значительное место отводилось увековечиванию памяти о героях революции, в качестве предтеч которых рассматривались руководители народных восстаний. Романовский обелиск у входа в Верхний сад в 1918 г. получил новое название - «Революционным мыслителям и деятелям борьбы за освобождение трудящихся». Вместо имен правителей на нем вырезали фамилии 19 революционных мыслителей, орла и гербы сбили. В центральном картуше вместо изображения Георгия Победоносца появилась надпись «Р.С.Ф.С.Р.», ниже - «Пролетарии всех стран, соединяйтесь!». Позже, в 1966 г. монумент перенесли в центр сада. В то же время многие новые монументы оказались недолговечными, поскольку создавались из непрочных материалов. Открытие памятника Ивану Болотникову, которого стали рассматривать как руководителя крестьянского восстания, по проекту скульптора С.В. Кольцова, намечалось в Москве 4 ноября 1919 г., но за два дня до этого он рассыпался от мороза [15].

Напротив, популярный герой предыдущей эпохи Иван Сусанин был отнесен к «царским слугам». В 1918 г. с памятника в Костроме были сброшены бюст Михаила Романова и скульптура Сусанина, а сама площадь получила имя Революции. Колонну закрыли деревянным обелиском с портретами революционных вождей, увенчанным красным флагом. Через 10 лет деревянный обелиск пришел в негодность и колонну сбросили с постамента. Окончательно памятник снесли уже в 1934 году. Было также прекращено строительство памятника Минину в Нижнем Новгороде и монумента в честь 300-летия Дома Романовых в Костроме, на постаменте которого в 1928 г. установили статую В.И. Ленина.

Звучали предложения снести и памятник Мартоса в Москве, пустив фигуры на переплавку [4, с. 35,45$]$. Но памятник уцелел, лишь в связи с реконструкцией Красной площади и возведением Мавзолея Ленина в 1931 г. его перенесли к Покровскому собору. Сохранился и монумент «Тысячелетие России». В то же время храмы, посвященные событиям Смуты, были закрыты. В перестроенном здании собора Феодоровской иконы Божьей матери, закрытом в 1932 г., стал работать молокозавод. В 1936 г. был снесен собор Казанской иконы Божьей матери в Москве.

С конца 1930-х гг. в советской пропаганде и тесно связанной с ней мемориальной политике происходил новый поворот: в условиях нарастания внешней угрозы и постепенной стабилизации внутренней ситуации она отказывалась от классовых принципов в пользу патриотических ценностей. Это привело к возвращению в мемориальное пространство имен Сусанина, Минина и Пожарского. В 1939 г. Молвитинский район Ярославской области был переименован в Сусанинский, а его центр, село Молвитино, - в село Сусанино. В настоящее время Сусанин изображен на гербе и флаге района.

Использование патриотических идей в советской пропаганде усилилось в годы Великой Отечественной войны. 7 ноября 1943 г. в Горьком на Советской (бывшей Благовещенской) площади был установлен памятник Минину работы скульптора А.И. Колобова из бетона, выкрашенного под бронзу. Площадь также получила название Минина и Пожарского. Уже после войны, в 1955 г. первому из них в начале примыкавшей к площади улице Минина был установлен еще один памятник бюст работы А.В. Кикина. В 1985 г. пришедший в негодность памятник А.И. Колобова отправили на реставрацию в Балахну, на родину Минина, а в Горьком через четыре года установили новый бронзовый памятник работы скульптора О.К. Комова, архитекторов Е.И. Кутырева, В.В. Воронкова и Н.И. Комовой. Надпись на табличке гласит: «Великому патриоту земли Русской Козьме Минину». Отреставрированный памятник в 1990 г. был установлен на Советской площади в Балахне, в 2007 г. получившей название Минина.

Об изменении отношения Советского государства к мемориальному наследию свидетельствовала и судьба монумента «Тысячелетие России», значительно пострадавшего в период нацистской оккупации Новгорода. Немецкое командование организовало работы по демонтажу памятника с целью его вывоза в Германию. По решению Комитета по 
делам архитектуры при СНК СССР и исполкома Ленинградского областного Совета депутатов трудящихся памятник восстановили в числе первых объектов уже в начале ноября 1944 года [12, с. 10].

В том же 1944 г. памятник Пожарскому заказало Главное политическое управление Красной армии по просьбе командования, размещавшегося в то время в Суздале Винницкого военного училища. Памятник-бюст был выполнен скульптором 3.И. Азгуром в 1950 г., а открыт только в 1955 г., но не на могиле Пожарского, а в сквере у стен Спасо-Евфимиева монастыря, поскольку на его территории тогда размещалось закрытое детское учреждение. В честь Пожарского были названы улицы во многих городах - Владикавказе, Владимире, Суздале, Волгограде, Красноярске, Можайске, Липецке, Перми, Саранске, Хабаровске, Химках, Ярославле, Керчи, Харькове, Алма-Ате, а в Томске, кроме улицы, еще и переулок. Его имя также было присвоено электропоезду и военному крейсеру.

В то же время в советской мемориальной культуре увековечивалась память о руководителях народных движений. В Туле в 1953 г. был установлен гранитный обелиск с надписью: «Здесь в 1607 году в стенах Кремля оборонялись восставшие крестьяне под руководством Болотникова». Еще один памятник Болотникову был установлен в Калуге, где он несколько месяцев держался против осаждавших город правительственных войск, а в Каргополе Архангельской области, где его утопили, - памятный знак. В честь Болотникова были названы улицы в Москве, Туле, Калуге, Магнитогорске, Тюмени, Коломне, Казани, Горловке, Нижнем Новгороде, Каргополе, Арзамасе, Серпухове, Томске, Владимире, в Липецке - переулок, а в Краснодаре и Минске- улицы и переулки.

В 1967 г. в Костроме возле Молочной горы был установлен новый памятник Сусанину по проекту скульптора Н.А. Лавинского. В отличие от предыдущего он был лишен каких-либо монархических и религиозных символов. Надпись гласила: «Ивану Сусанину патриоту земли русской». В том же году был открыт музей Сусанина в церкви Вознесения, построенной в XVII веке. Экспозиции музея рассказывают о событиях Смутного време- ни, подвиге Сусанина и повторивших его в годы Великой Отечественной войны людях, об отражении этого подвига в произведениях искусства и литературы. В 1988 г. на холме над Чистым болотом, на месте бывшей деревни Анферово, через которую, как считается, вел Сусанин врагов, был установлен памятный знак - валун с надписью: «Иван Сусанин 1613». Имя Сусанина носят улицы в Москве, Калининграде, Костроме, Краснодаpe, Петрозаводске, Днепре, Донецке, Запорожье, Харькове, Алма-Ате, Софии. Оно было также присвоено нескольким морским и речным кораблям.

В начале 1990-х гг. мемориальная политика в России пережила очередной поворот, обусловленный общими переменами в жизни страны. Одной из его характерных особенностей стало возвращение религиозных символов в мемориальную сферу. На Красной площади в 1993 г. был восстановлен собор Казанской иконы Божьей матери по проекту Г. Макеева и О. Журина, материалы которому передал архитектор и реставратор П. Барановский, успевший сделать необходимые обмеры собора перед его разрушением.

В 1992 г. площади Революции в Костроме было возвращено имя Сусанина. В последующие два с половиной десятилетия появилось значительное количество новых памятников участникам событий Смутного времени. Так, в 1998 г. был открыт памятник Пожарскому работы Т.С. Рыжовой и П.Н. Гусева на его родине в селе Пурех городского округа Чкаловск Нижегородской области. Площадь перед домом культуры, где был установлен памятник, также получила его имя. В 2004 г. еще один памятник - бюст Пожарского работы Ю.Ф. Иванова и С.В. Киреева был установлен в подмосковном городе Зарайске, где князь служил воеводой в начале XVII в. и где начал собирать один из отрядов Первого ополчения.

Повышенный интерес к событиям Смутного времени вызвало введение в 2005 г. нового государственного праздника 4 ноября Дня народного единства, заменившего годовщину Великой Октябрьской социалистической революции. Новый праздник был приурочен к давно забытой в массовом сознании дате капитуляции в Москве в 1612 г. иностранного 
гарнизона и к церковному празднику - Дню Казанской иконы Божией Матери, не встретив понимания у значительной части общества. Поэтому новые мемориальные объекты в честь событий и героев Смутного времени фактически создавали новую разметку пространства исторической памяти.

В Нижнем Новгороде на площади Народного единства 4 ноября 2005 г. была открыта немного уменьшенная по сравнению с оригиналом копия московского памятника Минину и Пожарскому, выполненная 3.К. Церетели. В том же году памятник Пожарскому был установлен в поселке Борисоглебском Ярославской области перед зданием поселковой администрации, где ранее стоял памятник В.И. Ленину. Над местом погребения Пожарского в 2008 г. установили плиту и памятный крест, а на следующий год восстановили мраморный склеп, торжественно открытый в День народного единства Президентом России Д.А. Медведевым [7]. Наконец, в 2010 г. на территории Ярославского историко-архитектурного музея-заповедника была открыта стела «Клятва князя Пожарского», увенчанная крестом. С апреля по июль 1612 г. в связи с оккупацией Москвы Ярославль считался столицей, и именно здесь формировалось Второе ополчение во главе с князем Пожарским. Именем Пожарского названа также заложенная в 2016 г. атомная подводная лодка стратегического назначения.

Хотя в современной России сохраняются объекты, посвященные лидерам народных движений, в мемориальной сфере постепенно утверждаются другие принципы. Об этом свидетельствуют возвращение самого понятия Смуты и отказ от присущего советской историографии разделения ее событий на крестьянскую войну и иностранную интервенцию. В 2007 г. к 400-летней годовщине сражения на реке Восьме, в котором Болотников потерпел решающее поражение от правительственных войск, недалеко от села Богословского был установлен памятный знак в виде двух секир, символизирующий бессмысленность гражданской междоусобицы.

Все более расширяется мемориальный ряд героев и участников Смутного времени. Еще в 1989 г. был причислен к лику святых патриарх Иов, а в 2012 г. ему был установлен памятник работы Ю. Хмелевского на его родине, в городе Старице Тверской области. В честь М.В. Скопина-Шуйского установлены памятники в городах Калязине и Кохме, в поселке Борисоглебском Ярославской области, в селе Городне Тверской области. Кроме того, празднование в 2009 г. 400-летия его похода ознаменовалось установлением целого ряда памятных досок, стел, мемориальных камней и поклонных крестов в Дмитрове, под Ярославлем и в других местах.

К числу героев «второго плана», образы которых также получили свое выражение в мемориальной сфере в последние годы, можно отнести казачьего атамана Ивана (Смагу) Чершенского. В отличие от большинства других атаманов, он ориентировался на московские власти. Согласно местным преданиям Смага Чершенский после избрания царем Михаила Романова основал в его честь на Дону в 1613 г. станицу Романовскую (в настоящее время Волгодонского района Ростовской области). Несмотря на то что за 200 лет станица не раз меняла свое местоположение из-за разливов Дона и набегов, в 2008 г. в ней был установлен памятник Смаге Чершенскому, хорошо вписавшийся в современный символический ландшафт. В 2015 г. в Угличе открыли памятник царевичу Дмитрию. А после установления в Орле памятника Ивану Грозному стал обсуждаться вопрос о возведении памятника и Борису Годунову, с которым связано начало Смуты [13; 14].

Еще один виток интереса к событиям Смутного времени вызвало 400-летие Дома Романовых в 2013 году. В частности, был восстановлен Романовский обелиск в Александровском саду. Неподалеку от него в честь столетия причисления патриарха Гермогена к лику святых был открыт памятник скульптоpa С.А. Щербакова и архитектора И.Н. Воскресенского. Был восстановлен и собор Феодоровской иконы Божьей матери в Санкт-Петербурге.

Результаты. Таким образом, в мемориализации событий и участников Смутного времени можно выделить ряд периодов, тесно связанных с соответствующими периодами в истории Российского и Советского государства и осуществлявшейся политикой памяти: дореволюционный, советский и постсоветский. При 
этом каждый из них, в свою очередь, делится на два этапа. В XVII-XVIII вв. почитание событий, героев и мучеников Смуты принимало присущие этому времени религиозные формы. B XIX в. мемориальная политика отделяется от церкви и становится самостоятельной сферой деятельности. В то же время усиливается ее зависимость от государства, особенно в эпоху царствования Николая I, о чем свидетельствует формирование культа Сусанина. Наиболее крупной идеологической кампанией императорской России, вызвавшей значительный рост числа мемориальных мероприятий и объектов, посвященных Смутному времени, стало празднование 300-летия Дома Романовых.

Реализация программы монументальной пропаганды после революции 1917 г. предусматривала свержение прежних памятников монархического содержания и установление новых, в том числе посвященных народным движениям и их лидерам, одним из которых считался Болотников. Массовый характер носило закрытие и разрушение храмов, в том числе и посвященных Смутному времени. Но с конца 1930-х гг. советская мемориальная политика вернулась к патриотическим принципам, что привело к созданию новых памятников Сусанину, Минину и Пожарскому.

Современный период в развитии советской мемориальной политики характеризуется восстановлением разрушенных в годы советской власти храмов и установлением новых памятников участникам Смутного времени, в том числе тем, которые являлись «фигурами умолчания». Значительный импульс созданию мемориальных объектов в честь событий и героев Смутного времени придал День народного единения. Во многих местах появились памятники регионального и локального значения, призванные не только «вписать» судьбу отдельной местности в общую историю страны, но и придать ей дополнительную привлекательность в туристическом отношении.

\section{ПРИМЕЧАНИЕ}

${ }^{1}$ Статья подготовлена в рамках гранта Российского научного фонда «Войны и население юга России в XVIII - начале XXI в.: история, демография, антропология» (проект № 17-18-01411).

\section{СПИСОК ЛИТЕРАТУРЫ}

1. Ассман, А. Длинная тень прошлого: мемориальная культура и историческая политика / А. Ассман. - М. : Новое литературное обозрение, 2014. $-323 \mathrm{c}$.

2. Ассман, А. Новое недовольство мемориальной культурой / А. Ассман. - М. : Новое литературное обозрение, 2016. -232 с.

3. Ассман, Я. Культурная память. Письмо, память о прошлом и политическая идентичность в высоких культурах древности / Я. Ассман. - М. : Языки славянской культуры, 2004. - 363 с.

4. Вдовин, А. И. Русские в ХХ веке: Факты. События. Люди / А. И. Вдовин. - М. : Олма-Пресс, 2004. $-446 \mathrm{c}$.

5. Вострышев, М. Москва православная. Все храмы и часовни / М. Вострышев. - М. : Алгоритм, 2012. $-544 \mathrm{c}$.

6. Время - История - Память: проблемы исторического сознания / отв. ред. Л. П. Репина. - М. : ИВИРАН, 2007.-319 с.

7. Дмитрий Медведев открыл мавзолей Пожарского в Суздале (Владимирская область). - Электрон. текстовые дан. - Режим доступа: https:// regnum.ru/news/1221644.html (дата обращения: 25.08.2018).

8. Карнишин, В. Ю. 300-летиеДома Романовых: за фасадом официального празднования / В. Ю. Карнишин // Известия высших учебных заведений. Поволжский регион. Гуманитарные науки. - 2013. - № 1. C. 5-10.

9. Клейтман, А. Л. События Смутного времени начала XVII столетия в исторической памяти населения Нижнего Поволжья XVIII - начала XX вв. / А. Л. Клейтман // Альтернативы, переломные пункты и смены режима в истории России : материалы I Междунар. науч. конф. молодых русистов будапештского центра русистики от 19-20 мая 2014 г. Будапешт : Russica Pannonicana, 2015. - C. 45-54.

10. Кожевников, Р. Ф. Скульптурные памятники Москвы : путеводитель / Р. Ф. Кожевников. - М. : Московский рабочий, 1983. - 320 с.

11. Леонтьев, Я. Причины забвения и реабилитация полководца М.В. Скопина-Шуйского / Я. Леонтьев // Научный православный взгляд на ложные исторические учения : материалы совместной конф. Русского культурно-просветительного фонда им. Св. Василия Великого и ИРИ РАН. - М. : Русский издательский центр, 2011. - С. 180-193.

12. Маслова, Е. Н. Памятник «Тысячелетию России» / Е. Н. Маслова. - Л. : Лениздат, 1972. $102 \mathrm{c}$.

13. Нужно ли ставить памятник Борису Годунову? - Электрон. текстовые дан. - Режим доступа: http://www.aif.ru/dontknows/actual/nuzhno_li_ 
stavit_pamyatnik_borisu_godunovu (дата обращения: 16.08.2018).

14. Онищенко предложил поставить памятники Борису Годунову и княгине Ольге. - Электрон. текстовые дан. - Режим доступа: https://360tv.ru/ news/kultura/onishenko-predlozhil-postavitpamyatniki-borisu-godunovu-i-knyagine-olge-76001/ (дата обращения: 16.08.2018).

15. Памятник Болотникову на Большой Тульской улице. - Электрон. текстовые дан. - Режим доступа: https://pastvu.com/p/62445 (дата обращения: 22.08.2018).

16. Память о войне 60 лет спустя: Россия, Германия, Европа / ред.-сост. М. Габович. - 2-е изд., испр. и доп. - Москва : Новое литературное обозрение, 2005. - 784 с. - (Библиотека журнала «Неприкосновенный запас»).

17. Патриот земли русской. Отражение подвига И. Сусанина в литературе и искусстве : рек. указ. лит. - Кострома : [б. и.], 1988. - 30 с.

18. Платонов, С. Ф. Смутное время. Очерк истории внутреннего кризиса и общественной борьбы в Московском государстве XVI и XVII веков / С. Ф. Платонов. - М. : АИРО-ХХІ ; СПб. : Дмитрий Буланин, 2007. - 204 с.

19. Политика памяти в России, странах ЕС и государствах постсоветского пространства: типология, конфликтный потенциал, динамика трансформации (стенограмма дискуссии) // Методологические вопросы изучения политики памяти : сб. науч. тр. / ред. А. И. Миллер, Д. В. Ефременко. - СПб. : Нестор-История, 2018. - С. 167-195.

20. Рикер, П. Память, история, забвение / П. Рикер.-М. : Изд-во гуманитарной литературы, 2004. $725 \mathrm{c}$.

21. Скрынников, Р. Г. Россия в начале XVII в. «Смуга» / Р. Г. Скрынников. - М. : Мысль, 1988. -203 с.

22. Сокол, К. Г. Монументальные памятники Российской империи : каталог / К. Г. Сокол. - М. : Вагриус Плюс, 2006. - 432 с.

23. Соловьев, С. М. Сочинения. В 18 кн. Кн. 4. История России с древнейших времен / С. М. Соловьев. - М. : Мысль, 1989. - 742 с.

24. Станиславский, А. Л. Гражданская война в России XVII в. Казачество на переломе истории / А. Л. Станиславский. - М. : Мысль, 1990. - 270 с.

25. Тюменцев, И. О. Смутное время в России начала XVII столетия. Движение Лжедмитрия II / И. О. Тюменцев. - М. : Наука, 2008. - 686 с.

26. Франция - память : сборник : пер. с фр. / П. Нора [и др.]. - СПб. : Изд-во СПбГУ, 1999. - 328 с.

27. Шалак, М. Е. Смутное время в оценках русских современников и историческое сознание российского общества XVII века / М. Е. Шалак // Известия вузов. Северо-Кавказский регион. Общественные науки. - 2004. - № 1. - С. 36-40.

\section{REFERENCES}

1. Assman A. Dlinnaya ten proshlogo: memorialnaya kultura $i$ istoricheskaya politika [A Long Shadow of the Past. Memorial Culture and Historical Policy]. Moscow, Novoe literaturnoe obozrenie Publ., 2014. 323 p.

2. Assman A. Novoe nedovolstvo memorialnoy kulturoy [New Dissatisfaction with Memorial Culture]. Moscow, Novoe literaturnoe obozrenie Publ., 2016.232 p.

3. Assman Ya. Kulturnaya pamyat. Pismo, pamyat o proshlom i politicheskaya identichnost $v$ vysokikh kulturakh drevnosti [Cultural Memory. Letter, Memory of the Past and Political Identity in High Cultures of Antiquity]. Moscow, Yazyki slavyanskoy kultury Publ., 2004. 363 p.

4. Vdovin A.I. Russkie v XX veke: Fakty. Sobytiya. Lyudi [Russians in the $20^{\text {th }}$ Century: Facts. Events. People]. Moscow, Olma-Press Publ., 2004. 446 p.

5. Vostryshev M. Moskva pravoslavnaya. Vse khramy i chasovni [Orthodox Moscow. All Temples and Chapels]. Moscow, Algoritm Publ., 2012. 544 p.

6. Repina L.P., ed. Vremya-Istoriya-Pamyat: problemy istoricheskogo soznaniya [Time - History Memory: the Problems of Historical Consciousness]. Moscow, IVI RAN, 2007.319 p.

7. Dmitriy Medvedev otkryl mavzoley Pozharskogo v Suzdale (Vladimirskaya oblast) [Dmitry Medvedev Opened Pozharsky's Mausoleum in Suzdal (Vladimir Oblast)]. URL: https://regnum.ru/ news/1221644.html (accessed 25 Aug. 2018).

8. Karnishin V.Yu. 300-letie Doma Romanovykh: za fasadom ofitsialnogo prazdnovaniya [The $300^{\text {th }}$ Anniversary of the House of Romanov: Behind the Facade of the Official Celebration]. Izvestiya vysshikh uchebnykh zavedeniy. Povolzhskiy region. Gumanitarnye nauki, 2013, no. 1, pp. 5-10.

9. Kleytman A.L. Sobytiya Smutnogo vremeni nachala XVII stoletiya $\mathrm{v}$ istoricheskoy pamyati naseleniya Nizhnego Povolzhya XVIII - nachala XX vv. [The Events of the Time of Troubles of the Early $17^{\text {th }}$ Century in the Historical Memory of the Lower Volga Region Population of the $18^{\text {th }}-$ Early $\left.20^{\text {th }} \mathrm{c}.\right]$. Alternativy, perelomnye punkty $i$ smeny rezhima $v$ istorii Rossii. Materialy I Mezhdunar. nauch. konf. molodyh rusistov budapeshtskogo tsentra rusistiki ot 19-20 maya $2014 \mathrm{~g}$. [Alternatives, Turning Points and Regime Changes in the History of Russia. Proceedings of the First International Scientific Conference of Young Rusists of Budapest Center for Russian Studies, May 19-20, 2014]. Budapest, Russica Pannonicana Publ., 2015, pp. 45-54.

10. Kozhevnikov R.F. Skulpturnye pamyatniki Moskvy: putevoditel [Sculptural Monuments of Moscow: Guide]. Moscow, Moskovskiy rabochiy Publ., 1983. 320 p. 
11. Leontyev Ya. Prichiny zabveniya i reabilitatsiya polkovodtsa M.V. Skopina-Shuyskogo [The Causes of Oblivion and Rehabilitation of Commander M.V. Skopin-Shuisky]. Nauchnyy pravoslavnyy vzglyad na lozhnye istoricheskie ucheniya. Materialy sovmestnoy konf. Russkogo kulturno-prosvetitelnogo fonda im. Sv. Vasiliya Velikogo i IRI RAN [Scientific Orthodox View on False Historical Teachings: Proceedings of the Joint Conference of the Russian Cultural and Educational Fund Named after St. Basil the Great and Institute of Russian History, Russian Academy of Sciences]. Moscow, Russkiy izdatelskiy tsentr, 2011, pp. 180-193.

12. Maslova E.N. Pamyatnik «Tysyacheletiyu Rossii» [The Monument to the "Millennium of Russia"]. Leningrad, Lenizdat Publ., 1972. 102 p.

13. Nuzhno li stavit pamyatnik Borisu Godunovu? [Do We Need to Erect a Monument to Boris Godunov?]. URL: http://www.aif.ru/dontknows/actual/ nuzhno li stavit pamyatnik borisu godunovu (accessed 16 Aug. 2018).

14. Onishchenko predlozhil postavit pamyatniki Borisu Godunovu i knyagine Olge [Onishchenko Proposed to Erect Monuments to Boris Godunov and Olga of Kiev]. URL: https://360tv.ru/news/kultura/ onishenko-predlozhil-postavit-pamyatniki-borisugodunovu-i-knyagine-olge-76001/ (accessed 16 Aug. 2018).

15. Pamyatnik Bolotnikovu na Bolshoy Tulskoy ulitse [Monument to Bolotnikov on Bolshaya Tulskaya Street]. URL: https://pastvu.com/p/62445 (accessed 22 Aug. 2018).

16. Gabovich M., ed. Pamyat o voyne 60 let spustya: Rossiya, Germaniya, Evropa [Memory of the War 60 Years Later: Russia, Germany, Europe]. Moscow, Novoe literaturnoe obozrenie Publ., 2005. 784 p. (Biblioteka zhurnala «Neprikosnovennyy zapas» ["Neprikosnovennyy zapas" Journal Library]).

17. Patriot zemli russkoy. Otrazhenie podviga I. Susanina v literature i iskusstve: rek. ukaz. lit. [Patriot of the Russian Land. Reflection of the Deed of I. Susanin in Literature and Art. Recommended Index of Literature]. Kostroma, 1988. 30 p.

18. Platonov S.F. Smutnoe vremya. Ocherk istorii vnutrennego krizisa i obshchestvennoy borby $v$ Moskovskom gosudarstve XVI $i$ XVII vekov [The Time of Troubles. The Essay of the History of Internal Crisis and Social Struggle in the Moscow State of the $16^{\text {th }}$ and $17^{\text {th }}$ Centuries]. Moscow, AIRO-XXI Publ.; Saint Petersburg, Dmitriy Bulanin Publ., 2007. 204 p. 19. Politika pamyati v Rossi, stranakh ES i gosudarstvakh postsovetskogo prostranstva: tipologiya, konfliktnyy potentsial, dinamika transformatsii (stenogramma diskussii) [The Policy of Memory in Russia, EU Countries and Former Soviet Union States: Typology, Conflict Potential, Dynamics of Transformation (Discussion Transcript)]. Miller A.I., Efremenko D.V., eds. Metodologicheskie voprosy izucheniya politiki pamyati: sb. nauch. tr. [Methodological Issues of Studying the Policy of Memory. Collection of Scientific Papers]. Saint Petersburg, Nestor-Istoriya Publ., 2018, pp. 167-195.

20. Riker P. Pamyat, istoriya, zabvenie [Memory, History, Oblivion]. Moscow, Izd-vo gumanitarnoy literatury, 2004. $725 \mathrm{p}$.

21. Skrynnikov R.G. Rossiya v nachale XVII v. «Smuta» [Russia in the Early $17^{\text {th }}$ Century. "The Time of Troubles"]. Moscow, Mysl Publ., 1988. 203 p.

22. Sokol K.G. Monumentalnye pamyatniki Rossiyskoy imperii: katalog [Monumental Statues of the Russian Empire. Catalogue]. Moscow, Vagrius Plyus Publ., 2006. 432 p.

23. Solovyev S.M. Sochineniya. V 18 kn. Kn. 4. Istoriya Rossii s drevneyshikh vremen [Compositions. In 18 Books. Book 4. History of Russia since Ancient Times]. Moscow, Mysl Publ., 1989. 742 p.

24. Stanislavskiy A.L. Grazhdanskaya voyna $v$ Rossii XVII v. Kazachestvo na perelome istorii [The Civil War in Russia of the $17^{\text {th }} \mathrm{c}$. Cossacks at the Turning Point of History]. Moscow, Mysl Publ., 1990. 270 p.

25. Tyumentsev I.O. Smutnoe vremya v Rossii nachala XVII stoletiya. Dvizhenie Lzhedmitriya II [The Trouble Time in Russia in the Early 17th Century. Movement of False Dmitry II]. Moscow, Nauka Publ., $2008.686 \mathrm{p}$.

26. Frantsiya - pamyat: sbornik: per. $s$ fr. [France - Memory. Collection. Translated from French]. Saint Petersburg, Izd-vo SPbGU, 1999. 328 p.

27. Shalak M.E. Smutnoe vremya $v$ otsenkakh russkikh sovremennikov i istoricheskoe soznanie rossiyskogo obshchestva XVII veka [The Time of Troubles in Assessments of Russian Contemporaries and Historical Consciousness of Russian Society of the $17^{\text {th }}$ Century]. Izvestiya vuzov. Severo-Kavkazskiy region. Obshchestvennye nauki, 2004, no. 1, pp. 36-40. 


\section{ИСТОРИЯ СМУТНОГО ВРЕМЕНИ}

\section{Information about the Authors}

Evgeny F. Krinko, Doctor of Sciences (History), Chief Researcher of the Laboratory of History and Ethnography, Southern Scientific Center, RAS, Prosp. Chekhova, 41, 344006 Rostov-on-Don, Russian Federation, krinko@mail.ru, https://orcid.org/0000-0003-3008-5626

Evgeniya M. Goryushina, Researcher, Political Research Laboratory, Southern Scientific Center, RAS, Prosp. Chekhova, 41, 344006 Rostov-on-Don, Russian Federation, esherder@gmail.com, https:// orcid.org/0000-0003-1800-9890

\section{Информация об авторах}

Евгений Федорович Кринко, доктор исторических наук, главный научный сотрудник лаборатории истории и этнографии, Южный научный центр РАН, просп. Чехова, 41, 344006 г. Ростов-на-Дону, Российская Федерация, krinko@mail.ru, https://orcid.org/0000-0003-3008-5626

Евгения Михайловна Горюшина, научный сотрудник лаборатории политических исследований, Южный научный центр РАН, просп. Чехова, 41, 344006 г. Ростов-на-Дону, Российская Федерация, esherder@gmail.com, https://orcid.org/0000-0003-1800-9890 